\title{
posibilidades de conocer Ia edad de una obra
}

\author{
J. CALLEJA \\ Dr. en Ciencios Químicas
}

\begin{abstract}
El problema de conocer la edad de una obra se presenta con cierta frecuencia, unas veces surgido de querellas entre arrendadores y arrendatarios idesahucios por realización de modificaciones por parte de los segundos en fincas de los primeros, sin la autorización de éstosl, y otras planteado por investigaciones de indole arquealógica. En el primer caso la ley fija un plazo de prescripción de los derechos del arrendador sobre el orrendatario, y de chí que el problema gire alrededor de la fecha de ejecución de la obra causa del desahucio. En el segundo, la naturaleza del tema es muy diferente $y$, en general, éste se plantea de forma que hay que determinar si los restos hallados en unas ciertas excavaciones son o no de la misma época que los encontrados en otras.
\end{abstract}

En varias ocasiones se ha suscitado en el I.T.C.C. el problema en sus dos facetas yo señalados.

En cualquier caso, y a falta de mejores indicios, hay que centrar la posibilidad de conocer la edad de una obra en los materiales con que ésta ha sido ejecutada $y$, más concretamente, en los materiales aglomerantes que. como activos y no inertes, están sujełos a una evolución con el tiempo.

Con este criterio se ha revisado una gran parte de las publicaciones sobre materiales de construcción editadas en buen número de países, $y$ aparecidas en los últimos diez años, con el desalentador resultado de no haber encontrado ni una sola referencia relativa al tema.

Con el mismo fin se ha indagado cerca de personas y centros que pudieran entender del asunto, con idéntico resultado negativo e impresiones pesimistas acerca del éxito del tema, por falto de antecedentes $y$ por su dificultad intrínseca.

No obstanfe, no se ha querido soslayar este esfudio sin antes poner una pequeñísima contribución personal, cuyo objeto no es otro que el de dejar sentada la dificultad y los múltiples inconvenientes con que el abordamiento del tema tropezaría. A ello va dedicado lo que sigue.

Según lo onteriormente expuesto, el problema de determinar la edad de una obra - elemento estructural se convierte, mediante un cambio de varioble, en el de determinar la edad del material aglomerante con que estón realizados tyeso, cal, cementol.

Las variables a estudiar para ello serían, en cada caso, las ligadas a los procesos de evolución que el material experimenta con el tiempo thidratación, carbonatación, endurecimiento, etc.l, en las hipótesis previas de que dichos procesos transcurren de manera continua y sólo dependen, prácticamente, del tiempo. Lo primera de estas hipótesis puede ser aceptable; la segunda, no, segứn se verá después.

En el caso de un hormigón o mortero, el problema se complica ya de antemano considerablemente, al ser punto menos que imposible separar el árido inerte del aglomerante activo, pues, de trabajar sobre el aglomerado en conjunto, habría que conocer dosificaciones, relación agualaglomerante $y$ alguno que otro dato más, todos los cuales, en general, y por la propia índole del problema, se desconocen. Tampoco se dispone, casi nunca, de muestras originales de los materiales empleados, cuyo estudio podría, como alternativa, suplir a los mencionados datos. 
Tratándose de un aglomerado hecho exclusivamente a base de la pasta pura del aglomerante lyeso sin áridos o pasta pura de cementol se simplifica algo el problema, pero tales circunstancias son muy improbables, particularmente en el coso del cemento. En el caso del yeso se dan, sin embargo, con bastante frecuencia, pero también es clerto que este caso es el que menor interés presenta.

No obstante, se vo a trator de plantear y resolver el caso del yeso sin áridos, como mós sencillo. Para ello, de las variables antes señaladas como necesarias para el estudio, se va a considerar la hidratación, ya que en el yeso, por constituir éste prácticamente una especie química única, el fenómeno es menos complejo de lo que es, por ejemplo, en el cemento.

Entre las variables que intervienen en el proceso se va a considerar el calor de hidratación, como magnitud estrechamente ligoda al mismo, y susceptible de ser determinada experimentalmente y expresada mediante una cifra concreta.

Se entiende por calor de hidratación, el calor desprendido por la transformación exotérmica, en sulfato cálcico dihidrato, del sulfato cálcico hemihidrato, producida en la reacción de éste con el agua. Se expresa en calorías por gramo de sulfato cálcico hemihidrato.

El calor de hidratación puede expresarse como diferencia de dos calores de disolución, dados también en calorías por gramo de susłancia: el del maferial sin hidrafar Isulfato cálcico hemihidrato en este casol y el del material hidratado [sulfato cálcico dihidratol. El segundo es siempre menor que el primero, puesto que la hidratación es exotérmica y el sistema cede calor Iprecisamente el de hidratación). Por ello, el cálculo del calor de hidratación se basa en la determinación previa de los calores de disolución de los materiales anhidros $\theta$ hidratados.

Calor de hidratación a una cierta edad de un aglomerante es, por lo tanto, la diferencia entre el calor de disolución del aglomerante anhidro y el calor de disolución del aglomerante hidratado, concretamente a esa edad.

Como es lógico, si el proceso de hidratación es continuo, ininterrumpido, tal como se ha admitido en la primera hipótesis, el calor de disolución del aglomerante hidrafado va siendo menor a medida que la edad crece. En consecuencia, el calor de hidratación crece con la edad. Los límites de valores entre los que puede moverse el calor de hidratación son, por consiguiente, cero para la edad cero lal no estar hidratado el aglomerante, los dos términos de la diferencia que expresa el calor de hidratación son iguales entre sí y coinciden con el calor de disolución del aglomerante anhidrol, y un valor móximo para la edad infinito (hidratación fotall, pues, en tol caso, el calor de hidratación viene dado por la diferencia entre un vaior constante $(e \mid$ calor de disolución del aglomerante anhidrol y un valor mínimo lel calor de disolución del aglomerante totalmente hidratadol.

los valores comprendidos entre cero y dicho valor máximo corresponden a edades intermedias.

Con estas ideas, se trata ahora de expresar los hechos utilizando los siguientes símbolos:

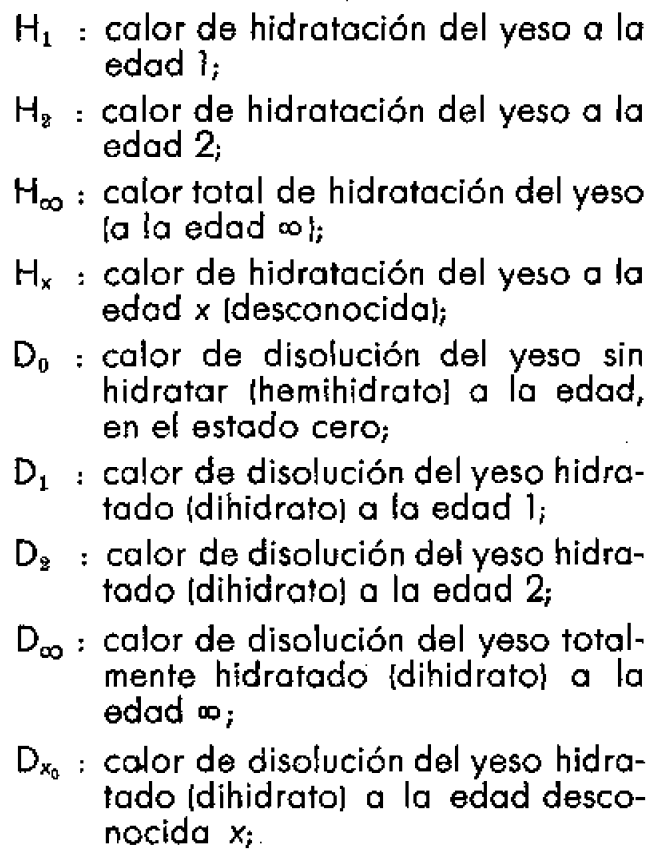

De lo anteriormente expuesto se deduce que:

$D_{0}>D_{1}>D_{2}>\ldots \ldots \ldots \ldots>D_{\infty}$ es decir, $D_{\infty}$ constituye un valor mínimo en la sucesión. 
$D_{0}$ es un valor constante para cada yeso $y$, dado que, como se decía, el yeso original suele ser desconocido en la generalidad de los casos, se puede tomar como valor $D_{0}$ el correspondiente a uno media de los relativos a los yesos más comunmente empleados en construcción (aproximación a).

Igualmente se tiene que:

$$
\begin{aligned}
& \mathrm{H}_{1}=\mathrm{D}_{0}-\mathrm{D}_{1} \\
& \mathrm{H}_{2}=\mathrm{D}_{0}-\mathrm{D}_{2} \\
& \dot{\cdot} \\
& \dot{H_{x}}=\mathrm{D}_{0}-\mathrm{D}_{\mathrm{x}_{0}}
\end{aligned}
$$

$D_{x_{0}}$ es, por lo tanto, un valor determinado experimentalmente.

$D_{\infty}$ es, de momento, un volor desconocido. Véase cómo podría determinarse experimentolmente, sin más datos ni elementos que los propios del problema planteado en su forma más general y, por consiguiente, imprecisa.

El yeso hidratado cuya edad se pretende determinar, y cuyo calor de disolución es, como queda indicado, $\mathrm{D}_{x_{0}}$, se somete a sucesivos procesos (n en total) de pulverización, amasado, fraguado e hidratación. Sean:

$D_{x_{1}}$ : calor de disolución del yeso hidratado de edad $x$, pulverizado y rehidratado una vez;

$D_{x_{3}}$ : calor de disolución del yeso hidratado de edad $x$, pulverizado y rehidratado una segunda vez, después de otra primera;

$D_{x_{n-1}}$ : calor de disolución del yeso hidratado de edad $x$, pulverizado y rehidratado uno n-l-ésima vez, después de ofra n-2-ésima;
$D_{x_{n}}$ : calor de disolución del yeso hidratado de edad $x$, pulverizado y rehidratado una n-ésima vez, después de otra n-l-ésima.

El proceso se repetiría hasta que dos valores consecutivos fuesen iguales, por ejemplo, hasta que:

$$
D_{x_{n}}=D_{x_{n-1}}
$$

Por lo vișto anteriormente tombién se verifica que:

$$
D_{x_{0}}>D_{x_{1}}>D_{x_{9}}>\ldots \ldots D_{x_{n-1}}>D_{x_{n}}
$$

$D_{x_{n}}$ es, por consiguiente, un valor que se determina experimentalmente. Por otra parte, la sucesión $D_{x}$ es convergente:

$$
\begin{gathered}
D_{x} \rightarrow D_{\infty} \\
y \text {, en el límite: } \\
D_{x_{n}}=D_{\infty}
\end{gathered}
$$

Se tiene asi el valor de $D_{\infty}$ determinodo experimentalmente, de manera indirecta laproximación bl.

De las expresiones III y IV se deduce entonces esta otra:

$$
H_{\infty}-H_{x}=D_{x_{0}}-D_{x_{n}}>0
$$

en la que todos los valores pueden determinarse experimentalmente.

Llomando $Q_{x}$ a la relación:

$$
Q_{x}=\frac{H_{\infty}-H_{x}}{H_{\infty}}=\frac{D_{x_{0}}-D_{x_{n}}}{D_{0}-D_{x_{n}}} \text { (VIII }
$$

se tendrá para (VIH) los siguientes valores extremos:

En el coso del yeso anhidro (hidratación nula o edad cerol, $D_{x_{\mathrm{a}}}=D_{\mathrm{v}}$ y, según (Ill), $H_{x}=0$, con lo cual $Q_{x}=1$.

En el caso del yeso tofalmente hidratado ledad $\infty$ ], $D_{x_{0}}=D_{x_{n}}=D_{\infty} y$, según (III) y IIVI, $H_{x}=H_{\infty}$, con lo cual $Q_{x}=0$.

Así pues, los valores de $Q_{x}$ (Vlli se mueven entre 1 y 0 para las edades cero $\theta$ infito respectivamente.

Los valores intermedios dependerían de la edad, siendo tanto más próximos a cero cuanto mayor sea la edad, puesto que con ésta $Q_{x} \rightarrow 0$, ya que $H_{x} \rightarrow H_{\infty}$, lo que, a su vez, resulta de que $D_{x_{0}} \rightarrow D_{x_{n}}$.

Se tendría así una correspondencia entre edades y valores experimentales de una 
magnitud físico-química lel calor de hidrataciónl íntimamente ligada al fraguado e hidratcición del yeso.

Para ello se han adoptado las aproximaciones a y b y, previamente, se hon aceptado las hipótesis de que la hidratación progresa continuamente con el tiempo ounque cada vez con moyor lentitud levolución retardadal, y de que esta evolución (o su retardol depende sólo o muy principolmente del tiempo.

Esta segunda hipótesis no es en modo alguno aceptable, por cuanto que la hidratación no depende exclusivamente del tiempo, sino también de otros factores tales como: al finura del yeso anhidro: bl cantidad inicial de agua de amasado; c) porosidad del material fraguado $y$ ambiente de conservación [condiciones de desecación o humectociónl, etc.

En cuanto a la finura del yeso anhidro, y a la cantidad de agua de amasado, es evidente que, de dos muestras de un mismo yeso, una más gruesa y otra más fina, amasados al mismo tiempo $y$ en las mismos condiciones, la más fina requiere mós agua para alcanzar una misma consistencia o plasticidad dadas.

Por ello y por ser mós fina, la hidratación de sus partículas penetra más y progresa con mayor velocidod, por lo que, a una misma edad, el valor de $\mathrm{D}_{x_{0}}$, así. como los de $H_{x}$ y $Q_{x}$ serían distintos de los correspondientes a la muestra más gruesa.

La porosidad del yeso fraguado y las condiciones de humedad y temperatura del ambiente de conservación influyen también en la velocidad de la hidratación, pues, como es lógico, ésta es distinta en ambientes húmedos y calientes que en fríos y secos.

Por todo ello puede concluirse que no existe uno correspondencia biunívoca entre edades y grados de hidratación, en términos de los valores $Q_{x}$ definidos en (VIII), dada la influencia de los factores señalados, entre otros que también pueden influir. Es decir, puede darse el caso de que para yesos de una misma edad resulten valores diferentes de $Q_{x}$ y, a la recíproca, que yesos con valores de $Q_{x}$ análogos tengan edades muy diferentes.

Incluso la validez de la primera hipótesis es asimismo discutible, por cuanto que a la hidratación total no se llega ni aún en un tiempo infinito. Responde más a la realidad la idea de que la hidratación tiene un límite variable, dependiente de una serie de factores análogos a los antes considerados. Es decir, a partir de una cierta edad, el yeso no experimenta prácticamente ninguna variación, por lo que, tampoco habría variación en los valores de $Q_{x}$, dándose una vez más la falta de correspondencia biunívoca: a un mismo valor de $Q_{x}$ corresponderian edades diferentes.

Las consideraciones hechas acerca del color de hidratación tomado como variable para estudiar la edad del yeso fraguado, son válidas para cualquier otra magnitud físico-química dependiente del proceso, en la que se basase el estudio del probiema. Lo mismo ocurre respecto de las características mecónicas (resistencias).

De igual manera, todas las consideraciones precedentes hechas para el yeso son aplicables a las cales y los cementos considerados en estado de pasta pura. Si se trata de morteros u hormigones, ya queda indicado que la complejidad del problema es aún mayor.

Tampoco puede pensarse en métodos químicos para la resolución del mismo, dado que la composición de los aglomerantes varía con el tiempo en virtud de los nuevos conocimientos que van adquiriéndose y de la evolución continua de las materias primas utilizadas y de los métodos de fabricación. Aun en este caso, sería preciso operar con cifras medias estadísticas, lo que daría a cualquier método ideado uno imprecisión que le haría inepto para el fin propuesto.

En conclusión: no se ve ninguna posibilidad de resolver por vía química o físicoquímica el problema de determinar la edad de una obra. 